\title{
Unusual ionospheric absorption characterizing energetic electron precipitation into the South Atlantic Magnetic Anomaly
}

\author{
Masanori Nishino $^{1}$, Kazuo Makita ${ }^{2}$, Kiyofumi Yumoto $^{3}$, Fabiano S. Rodrigues ${ }^{4}$, Nelson J. Schuch ${ }^{5}$, and Mangalathayil A. Abdu ${ }^{4}$ \\ ${ }^{1}$ Solar-Terrestrial Environment Laboratory, Nagoya University, Toyokawa 442-8507, Japan \\ ${ }^{2}$ Basic Education Series, Physics, Takushoku University, Hachioji, Tokyo 193-8585, Japan \\ ${ }^{3}$ Department of Earth and Planetary Sciences, Kyushu University, Fukuoka 812-8581, Japan \\ ${ }^{4}$ INPE, Sao Jose dos Campos, Sao Paulo 12201-970, Brazil \\ ${ }^{5}$ INPE, Southern Space Research Center, Rio Grade de Sul 97119-900, Brazil
}

(Received December 7, 2001; Revised September 25, 2002; Accepted September 25, 2002)

\begin{abstract}
An imaging riometer (IRIS) was installed newly in the southern area of Brazil in order to investigate precipitation of energetic electrons into the South Atlantic Magnetic Anomaly (SAMA). An unusual ionospheric absorption event was observed in the nighttime $(\sim 20 \mathrm{~h} \mathrm{LT})$ near the maximum depression $\left(D_{s t} \sim-164 \mathrm{nT}\right)$ and the following positive excursion during the strong geomagnetic storm on September 22-23, 1999. The unusual absorption that has short time-duration of 30-40 min shows two characteristic features: One feature is a sheet structure of the absorption appearing at the high-latitude part of the IRIS field-of-view, showing an eastward drift from the western to the eastern parts and subsequent retreat to the western part. Another feature is a meridionally elongated structure with a narrow longitudinal width $(100-150 \mathrm{~km})$ appearing from the zenith to the low-latitude part of the IRIS fieldof-view, enhanced simultaneously with the sheet absorption, and is subsequently changed to a localized structure. These features likely characterize precipitation of energetic electrons into the SAMA ionosphere, associated with substorm occurrences during the strong geomagnetic storm. From the eastward drift $(\sim 250 \mathrm{~m} / \mathrm{s})$ of the sheet absorption, precipitating electrons are estimated to be $\sim 20 \mathrm{keV}$ energies, assuming plasmaspheric electric fields of $1.8 \mathrm{mV} / \mathrm{m}$. However, no ionospheric effect due to the precipitating electrons was definitely detected by the ionosonde measurements at Cachoeira Paulista, separated eastward by about $1000 \mathrm{~km}$ from the IRIS station.
\end{abstract}

\section{Introduction}

It is generally understood that quasi-trapped particles in the inner radiation belt sink to the South Atlantic Magnetic Anomaly (SAMA) which is characterized by a global minimum in the Earth's total magnetic field intensity. Possible aeronomic effects by particle precipitation into the SAMA region were reviewed so far by several literatures (e.g., Paulikas, 1975; Gledhill, 1976: Pinto and Gonzalez, 1989).

On the ground-based observations, ionization effects induced by precipitation of energetic electrons were investigated by broad-beam $30 \mathrm{MHz}$ riometers and very-lowfrequency (VLF) techniques. The riometer absorption at Atibaia in Brazil indicated an eastward drift of about 100 $\mathrm{m} / \mathrm{s}$, associated with a sudden commencement followed by a strong geomagnetic storm (Abdu et al., 1973). Phase recordings of $13.6 \mathrm{kHz}$ Argentina VLF signals at Atibaia in Brazil showed significant perturbations due to the lowering of the VLF reflection level, associated with the onset of geomagnetic disturbances (Abdu et al., 1981). Phase advances of the $13.6 \mathrm{kHz}$ Argentina VLF signals were linearly proportional to a logarithmic function of the intensity of the geomagnetic storm, given by the peak $D_{s t}$ (Pinto et al., 1990). Abdu and Batista (1977) revealed from the ionosonde measurements that sporadic $E$-layer enhancements over Cachoeira Paulista

Copy right (c) The Society of Geomagnetism and Earth, Planetary and Space Science (SGEPSS); The Seismological Society of Japan; The Volcanological Society of Japan The Geodetic Society of Japan; The Japanese Society for Planetary Sciences. $\left(22.7^{\circ} \mathrm{S}, 45.0^{\circ} \mathrm{W}\right)$, Brazil showed frequent nighttime occurrences of high blanketing frequencies $\left(f_{b} E s\right)$. They interpreted as a regular nighttime ionization source in the SAMA. Batista and Abdu (1977) exhibited significant enhancements in the sporadic- $E$ layer parameters over the geomagnetic anomaly for short periods (2-3 hours) following moderate magnetic disturbances.

On the balloon-borne experiments in the SAMA, Pinto and Gonzalez (1986) observed intensification of X-ray fluxes with energies between $30 \mathrm{keV}$ and $150 \mathrm{keV}$ in the atmosphere during a strong geomagnetic storm using an omnidirectional scintillation detector. They considered as the first evidence on the precipitation associated with the geomagnetic activity inside the anomaly region. Jayanthi et al. (1997) observed count rate increases of X-rays in the energy range of $15 \mathrm{keV}$ to $120 \mathrm{keV}$ during a mild storm on a stratospheric balloon experiment at $L=1.3$ in the SAMA.

Using the Injun 3 satellite measurements of $40 \mathrm{keV}$ precipitating electrons, Torr et al. (1975) have theoretically estimated that fluxes of precipitating electrons on $L=2$ in the SAMA reach $\sim 35$ times greater than the average flux on $L=2$ in the northern hemisphere. From a four-year survey by the Atmospheric Explorer Satellite (AE-C) over the SAMA, Gledhill and Hoffman (1981) demonstrated downward electron fluxes with low-energy $(0.2-26.1 \mathrm{keV})$ for $3<K_{p}<6$ in nighttime over the SAMA. Vampola and Gorney (1983) calculated energy deposition profiles from spectra of locally precipitating $36 \mathrm{keV}$ to $317 \mathrm{keV}$ electrons 


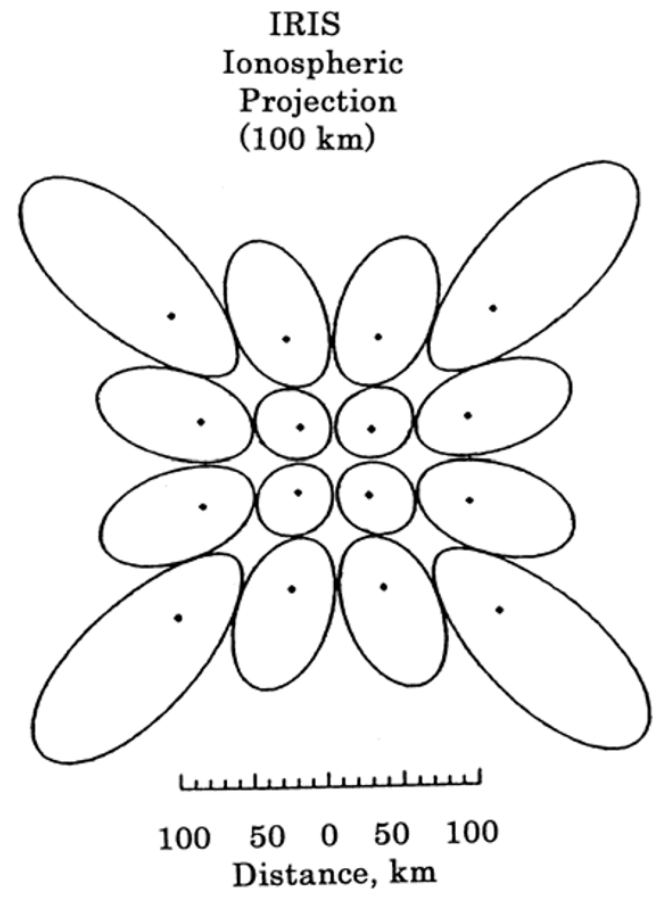

Fig. 1. The projection of half-power beam-width of two-dimensional $4 \times 4$ beams to the ionospheric layer of $100 \mathrm{~km}$ altitude.

observed by the S3-2 satellite, and predicted that precipitating electrons into the SAMA could produce ionization more than one order of magnitude greater than that expected from scattered H Lymann $\alpha$ radiation at night. Kohno et al. (1990) obtained global distributions of energetic electrons (0.19-3.2 MeV) from particle telescopes onboard the satellite OHZORA, in which electron fluxes were enhanced in the altitude range of $700-850 \mathrm{~km}$ over the SAMA.

As described above, although there are many reports from the ground-based, balloon-borne and satellite observations concerning particle precipitation into the SAMA region, there remain still major uncertainties in understanding of dynamics in the inner radiation belt and precipitation processes of energetic electrons into the SAMA, as indicated by the review paper of Pinto and Gonzalez (1989); (1) temporal and spatial precipitation changes from magnetically quiet to disturbed periods (2) the role of wave-induced precipitation processes.

Recently, Badhwar (1997) has revealed that the center of the SAMA drifting westward is located at $\sim 30^{\circ} \mathrm{S}$ and $\sim 45^{\circ} \mathrm{W}$ off the southeastern coastline of Brazil using does rate data in June 1995 from the Skylab and Mir orbital stations. The total intensity of the geomagnetic field is near the global minimum of 23,008 nT according to the International Geomagnetic Reference Field (IGRF) for 1990 (Takeda et al., 1999). Therefore it has become more significant to reinvestigate particle precipitation in Brazil. Aiming at continuous, long-term investigations of temporal and spatial changes of energetic electron precipitation into the SAMA from magnetically quiet and disturbed periods, we installed newly an imaging riometer at the INPE-SSO (Instituto Nacional de Pesquisas Espaciais, Southern Space Research Observatory, geographic coordinate, $29.4^{\circ} \mathrm{S}, 53.8^{\circ} \mathrm{W}$ ) near Santa Maria in
Brazil, where the total intensity of the geomagnetic field is about 22,855 nT in 2000 (Private communication, Trivedi). In this initial paper we present an ionospheric absorption event observed by the imaging riometer during the strong geomagnetic storm on September 22-23, 1999, and discuss primarily whether the absorption feature is characterized by energetic electron precipitation into the SAMA.

\section{Imaging Riometer}

An imaging riometer for ionospheric study (IRIS) which is capable of measuring shape, spatial scale and motion of ionospheric absorption was first developed at South Pole Station in the Antarctica in order to study dynamics of auroral particle precipitation in the high-latitude region (Detrick and Rosenberg, 1990). At present, multiple IRISs have been continuously operated in the arctic region and in the Antarctica (e.g., Stauning et al., 1992; Nishino et al., 1993). Most of these IRISs adopt the antenna system consisting of a twodimensional array with $8 \times 8$ half-wavelength dipoles with Butler-matrix phasing circuits at $38.2 \mathrm{MHz}$ or $30 \mathrm{MHz}$, by which cosmic radio noises can be detected by an angular resolution of half-power beam-width of $11^{\circ}$. The fastest timeresolution of IRIS two-dimensional data is 1 second. Quiet day curves (QDCs) necessary to reduce ionospheric absorption images from background cosmic radio noise are processed by a careful selection among about 10-days cosmic noise data on magnetically quiet days. Absorption intensities are reduced by subtraction between decreased cosmic radio noise and the QDCs. The QDCs are usually processed as the monthly background.

The IRIS newly installed at the INPE-SSO consists of a two-dimensional array with $4 \times 4$ half-wavelength dipoles at the operating frequency of $38.2 \mathrm{MHz}$. The separation between the dipoles is a half-wavelength. The two-dimensional array is aligned in the geographic north-south (N-S) and eastwest (E-W) directions, respectively. By the connection of the antenna array with Butler-matrix phasing circuits, the twodimensional $4 \times 4$ beams with a half-power beam-width of $22^{\circ}$ are directed upward to the ionospheric area centered at the zenith. The projection of the two-dimensional $4 \times 4$ halfpower beams to the ionospheric layer of $100 \mathrm{~km}$ altitude is shown in Fig. 1. The field-of-view (FOV) of the IRIS is approximately $330 \mathrm{~km}$ in the N-S and E-W cross-sections near the zenith.

The recording system of two-dimensional $4 \times 4$ cosmic radio noise data using a personal computer (PC) is basically the same performance with the Ny Ålesund (NYA) IRIS system (Sato et al., 1992). The two-dimensional $4 \times 4$ data are first converted to two-dimensional $8 \times 8$ ones by the use of interpolation and extrapolation calculations, and are led to the NYA IRIS procession system. Time variations of $38 \mathrm{MHz}$ radio noise and absorption intensities reduced from QDCs are printed as 8 channel stack plots for the N-S and EW cross-sections (see Fig. 4 and Figs. 3 and 5, respectively). The two-dimensional $8 \times 8$ data are further converted to twodimensional $16 \times 16$ data in the PC in order to obtain smooth absorption images with colors (see Plate 1). Thus absorption images are apparently represented by spatial resolution of about $10 \mathrm{~km} \times 10 \mathrm{~km}$ at the ionosphere of $100 \mathrm{~km}$ altitude near the zenith. 


\section{Observational Results}

The IRIS observation at INPE-SSO has been carried out continuously since the middle in May 1999. From initial analysis of IRIS data during the first year, it has been tentatively found that ionospheric absorption is usually observed in the time period from afternoon to evening with intensities of $0.2-0.5 \mathrm{~dB}$ during weak and moderate geomagnetic storms $\left(\left|D_{s t}\right|<100 \mathrm{nT}\right)$. This occurrence characteristic is consistent with the daily variation of the ionospheric $F$ region absorption associated with increases of $f_{o} F_{2}$ which were obtained from the statistical analysis of the riometer absorption on $25 \mathrm{MHz}$ at Ahmedabad in India (Abdu et al., 1967). Thus the absorption feature at INPE-SSO is identified as usual low-latitude $F$-region absorption. It has been also found that the usual $F$-region absorption first appears at the northernmost (low-latitude) part in the FOV, and is followed by expansion to the southern part (high-latitude) through the zenith, depending on magnetic activities. Apart from the usual $F$-region absorption, another absorption usually appears at the northernmost part in the FOV with localized enhancement near local noon, which is identified as usual $D$-region absorption (Abdu et al., 1967).

In this section we present an ionospheric absorption event observed during a strong geomagnetic storm occurred during September 22-24, 1999, assigned as the Space Weather month. Figure 2 shows a daily variation of $D_{s t}$ (hourly value) during September 21-24, 1999 (courtesy of WDCC2 for Geomagnetism, Kyoto University). A sudden commencement of the geomagnetic storm occurred at about 12 $\mathrm{h}$ UT on September 22, followed by positive fluctuation $\left(D_{s t}=20-30 \mathrm{nT}\right)$ during about $13 \mathrm{~h}-22 \mathrm{~h} \mathrm{UT}$ and a subsequent sharp decrease from about $22 \mathrm{~h} \mathrm{UT}$. The $D_{s t}$ attained to the minimum value $(-164 \mathrm{nT})$ near $0 \mathrm{~h} \mathrm{UT}$ on September 23, and recovered completely on September 25.

\subsection{The absorption event on September 22-23, 1999}

Figure 3 shows 24-hour variations of the absorption during September 22-23, 1999 in the upper panel, along with a time variation of the geomagnetic horizontal component at Hermunus (geomagnetic lat., $33.7^{\circ} \mathrm{S}$ ), South Africa, in the lower panel (courtesy of WDC-C2 for Geomagnetism, Kyoto University). Each stacked point in the absorption is plotted as averaged during 128 seconds. The absorption variations are displayed for N-S and E-W cross-sections centered near the zenith beam (N4E4). Note that N1-N4 and N5$\mathrm{N} 8$ beams represent the directions to low-latitude and highlatitude parts in the FOV, respectively.

Absorption increased on the all beams near 14h UT ( $\sim 1030$ LT) on September 22, followed by slowly varying absorption until about 20h UT during the positive geomagnetic excursion. This absorption showed uniform expansion in the whole FOV. Thereafter the absorption fluctuated during about 1940 UT to 2200 UT, and again slowly varied. The absorption feature described above is identified as the usual $F$-region absorption during the mild geomagnetic disturbance. Around 2240 UT the absorption suddenly disappeared from the eastern part, and thereafter showed an impulsive form, in particular, strong at the northernmost beam near 2330 UT. Here, it should be remarked that the absorption shows a spike form with strong intensity (maximum, $\sim 1.2 \mathrm{~dB}$ at the N4E6 beam) after about 2337 UT $(\sim 2000$
LT) and decays at about 0015 UT on September 23. Comparing with the geomagnetic variation at Hermunus, it is found that the spike form absorption is observed near the maximum depression and the following positive excursion.

In order to check the above absorption feature, we show time variations of $38 \mathrm{MHz}$ radio noises during $22 \mathrm{~h}-24 \mathrm{~h}$ UT by shorter averaging-time of 16 seconds in Fig. 4, along with the monthly QDCs determined from variations of cosmic radio noise on geomagnetic quiet-days in September. Strong interference radio noise was received from the eastern part to the zenith during about 2250-2310 UT, resulting in apparent zero absorption extended from the eastern part. Thereafter strongest interference radio noise appeared almost in the whole FOV at about 2310 UT, and disappeared temporally near 2322 UT and 2330 UT, resulting in impulsive absorption features. When the strongest interference noise became weak simultaneously in the all beams at about 2337 UT, background cosmic noise level started to decrease, which corresponds to the appearance of the spike form absorption by longer averaging time of 128 seconds, as shown in Fig. 3.

Figure 5 shows an enlarged time-variation of the spike form absorption for the E-W cross-section at the southern (high-latitude) beam (N7), from which we can find an eastward shift between the E2 and E5 channels in the FOV, as is displayed by a solid line, indicating an eastward drift of the sheet absorption. In the following we show two-dimensional images for the spike form absorption.

Plate 1 shows a time series of the absorption images from 2335:55 UT on September 22 to 0015:56 UT on September 23. Each absorption image is displayed as averaged during 64 seconds. Corresponding to the spike form variation, sheet absorption first appeared in the southern (high-latitude) part at 2336:59 UT with mild enhancement showing an extension toward the western area outside the FOV. The latitudinal width is small-scale of about $150 \mathrm{~km}$. Subsequently the sheet absorption was enhanced showing the eastward drift to the eastern part until 2346:35 UT, and thereafter retreated gradually to the western part showing the extension to the high-latitude part outside the FOV.

In Plate 1, we find another feature of meridionally elongated absorption with the longitudinal scale of 100-150 $\mathrm{km}$ that was enhanced at the northern (low-latitude) part at 2338:03 UT. The enhancement was simultaneous with the sheet absorption. The elongated absorption decayed at once at 2341:15 UT, but thereafter enhanced again at 2343:23 UT with a localized form. It should be noted that the localization within the one beam-width (Fig. 1) is caused by the effect of image procession, as described at the Section 2. The localized absorption stayed nearly in place until 2357:15 UT, and thereafter elongated to the low-latitude part with gradual decay.

As described above, the absorption feature shows unique form and motion, and thus may be identified as an unusual ionospheric absorption characterizing energetic electron precipitation into the SAMA.

\section{Discussion}

Measurements of energetic particles in the inner radiation belt have been carried out using some low-altitude satel- 


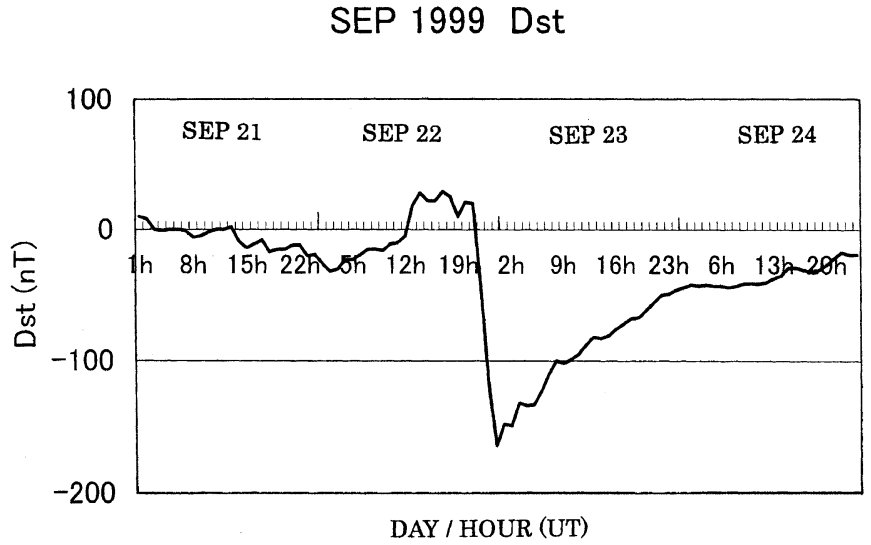

Fig. 2. A time variation of hourly $D_{s t}$ indices during September 21-24, 1999.

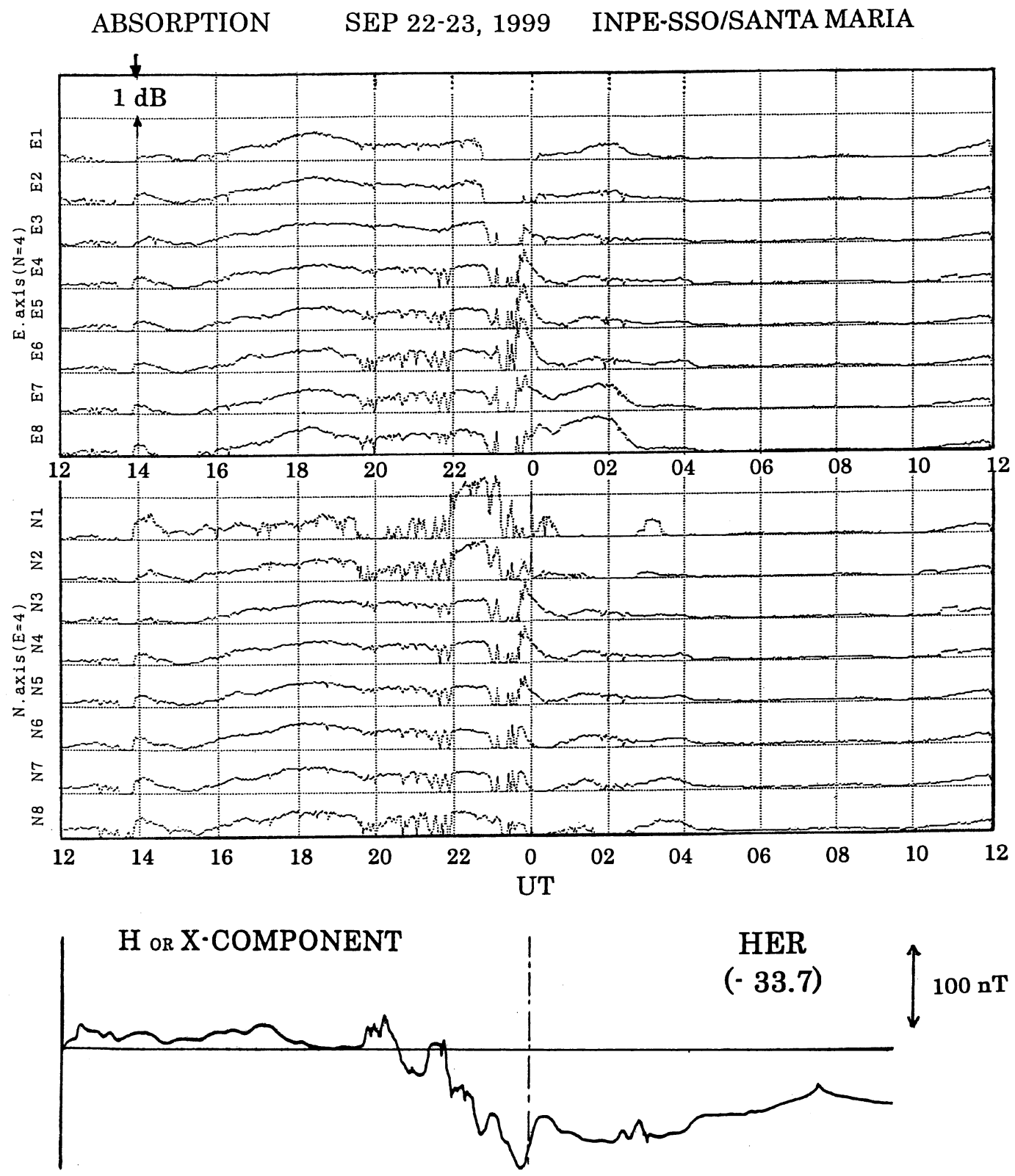

Fig. 3. Time variations of ionospheric absorption during September 22-23 in 1999 observed at INPE-SSO, Santa Maria in Brazil, along with the geomagnetic horizontal component at Hermunus (33. $7^{\circ} \mathrm{S}$ MLAT). The absorption variations are displayed on the N-S and E-W cross-sections centered at the N4E4 beam. Each stacked point is averaged during 128 seconds. 
$38 \mathrm{MHz}$ RADIO NOISE / QDC SEP 22, 1999 INPE-SSO

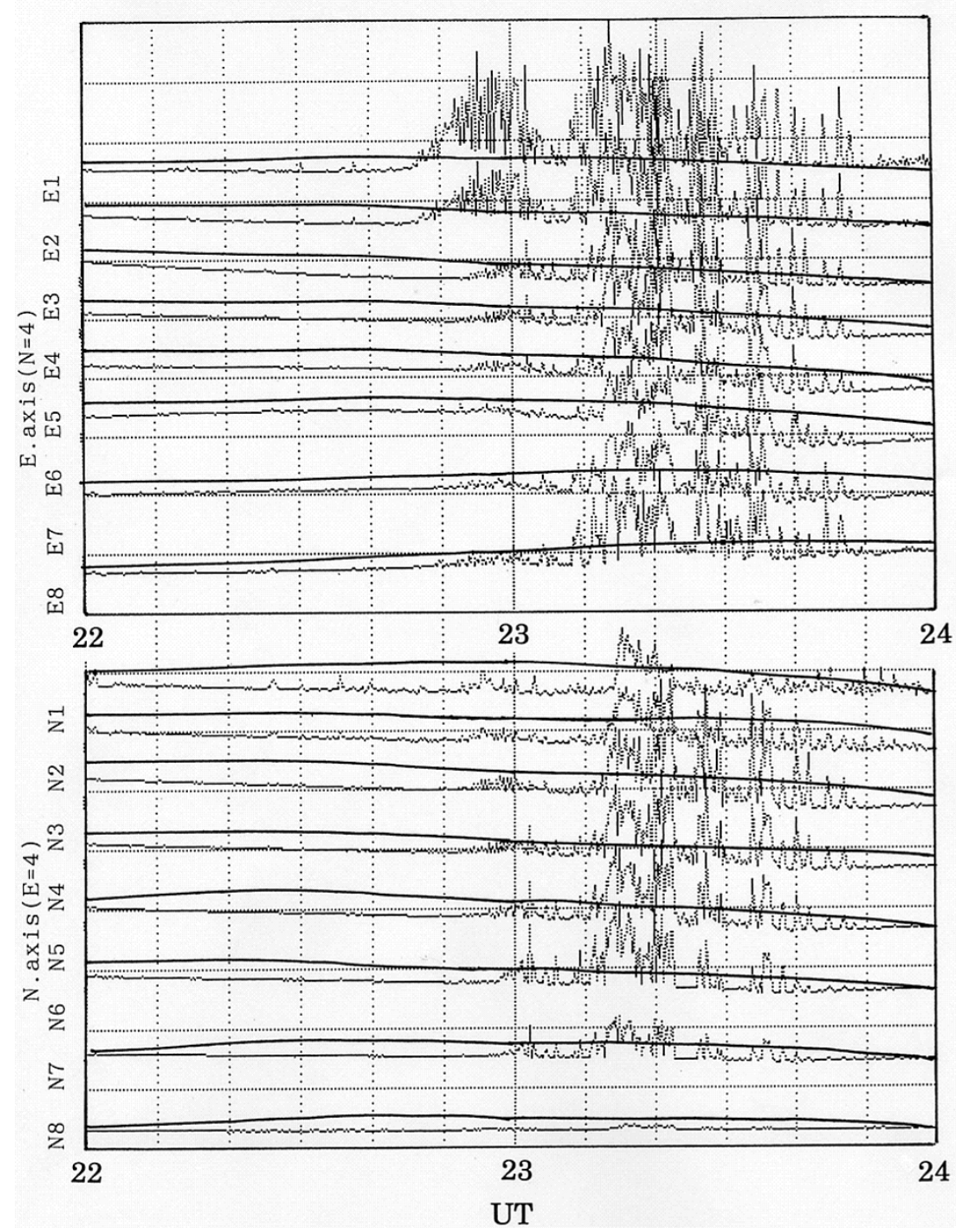

Fig. 4. Time variations of $38 \mathrm{MHz}$ radio noise during $22 \mathrm{~h}-24 \mathrm{~h}$ UT on September 22 and the monthly QDCs determined from background cosmic noise on magnetically quiet days. The variations are displayed on the N-S and E-W cross-sections centered at the N4E4 beam. Each stacked point is averaged during 16 seconds.

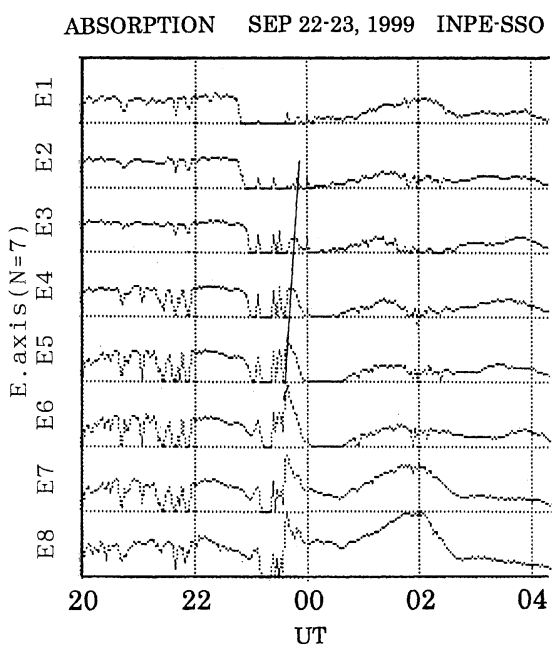

Fig. 5. Time variations of ionospheric absorption at the E-W cross-section at the southern beam (N7) during $20 \mathrm{~h}-04 \mathrm{~h}$ UT on September 22-23. Each stacked point is averaged during 128 seconds. lites. From the NOAA- 6 satellite observations $(h=850$ $\mathrm{km})$ Kikuchi and Evans (1989) demonstrated that energetic electron fluxes $(>30 \mathrm{keV})$ of pitch angle $90^{\circ}$ integrated over $L=1.3-1.4$ increased dramatically than the previous average value near the maximum depression $\left(D_{s t} \sim-300\right.$ nT). Baker et al. (1994) observed counting rate of $>460$ $\mathrm{keV}$ electrons near the magnetic equator by the CRRES spacecraft, in which abrupt electron increases extended from $L \sim 2$ to $L>6$ and often to the inner radiation belt of $L<2$ during geomagnetic storms. Obara et al. (2000) displayed an evident increase of 30-1100 keV energy electrons in the inner radiation belt of $L<1.5$ near the maximum depres$\operatorname{sion}\left(D_{s t} \sim-200 \mathrm{nT}\right)$ during the strong geomagnetic storm from the NOAA-12 satellite. Thus it is expected that energetic electrons in the inner radiation belt could precipitate into the SAMA ionosphere during the strong geomagnetic storm, taking account of a numerical simulation of electron pitch angle scattering in an asymmetric magnetic field environment (Abel and Thorne, 1999). 


\section{SEP 22-23, 1999 INPE-SSO}
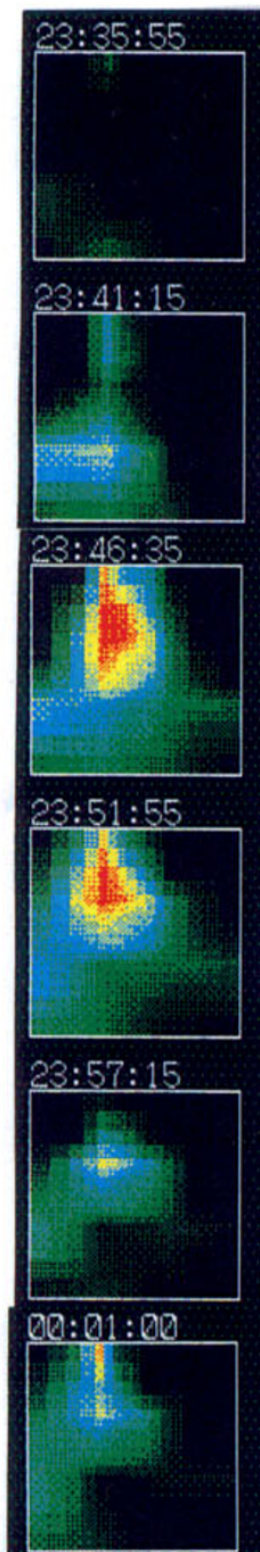

$000: 06: 20$

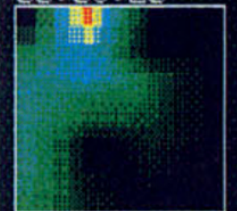

Q0]: $11: 40$

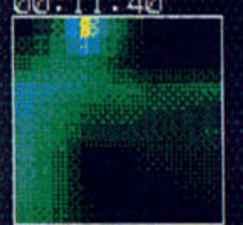

$20: 12: 44$

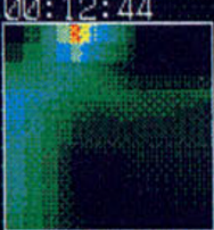

00: $13: 48$

$23: 42: 19$

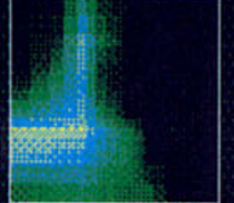

$23: 47: 39$
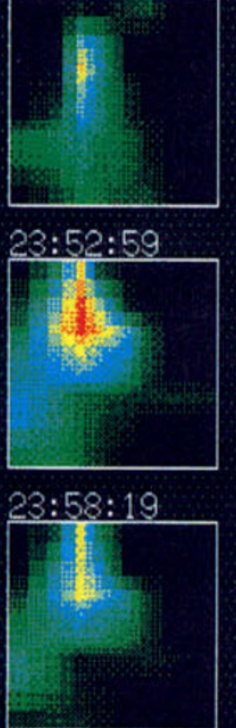

000:02:04

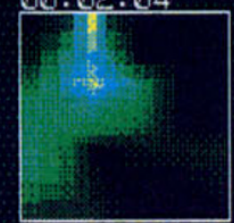

$00: 07: 24$
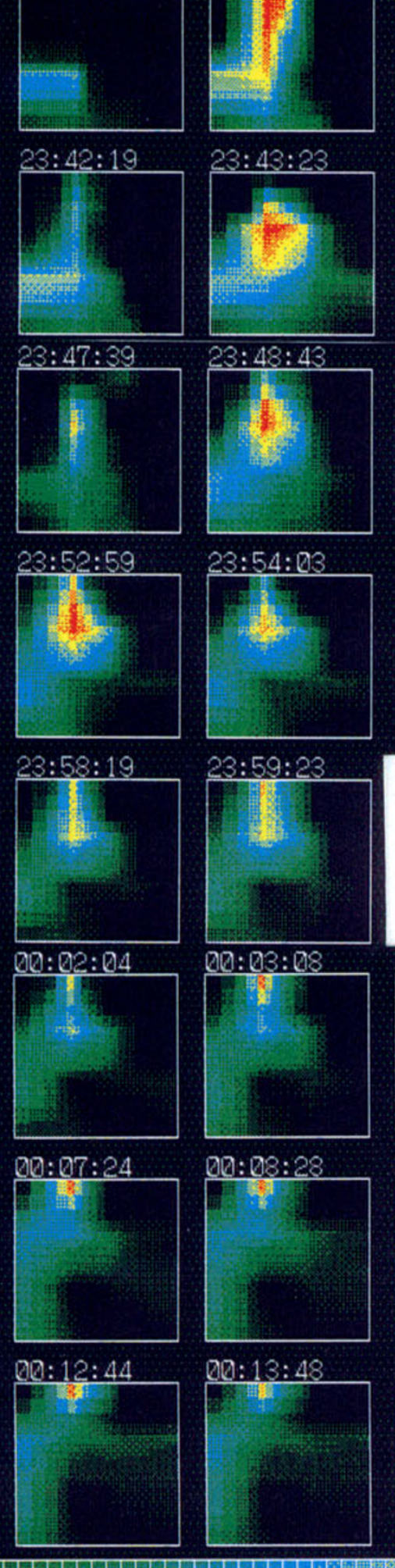

$23: 48: 43$

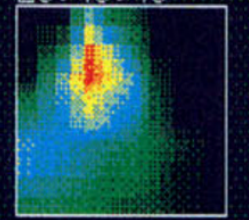

$23: 54: 03$

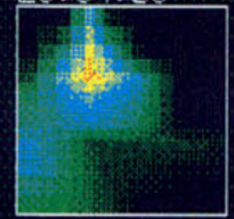

$23: 59: 23$

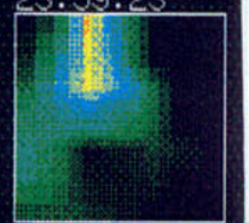

$00: 03: 08$

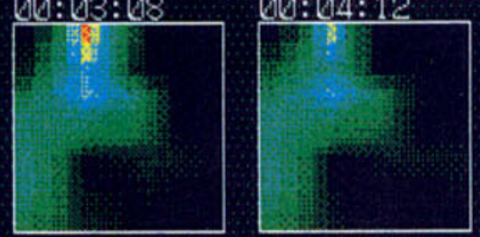

000:08:28

$000: 09: 32$

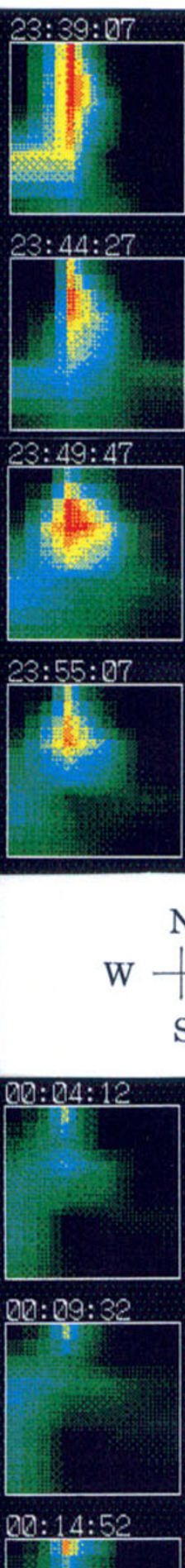

$00: 14: 52$
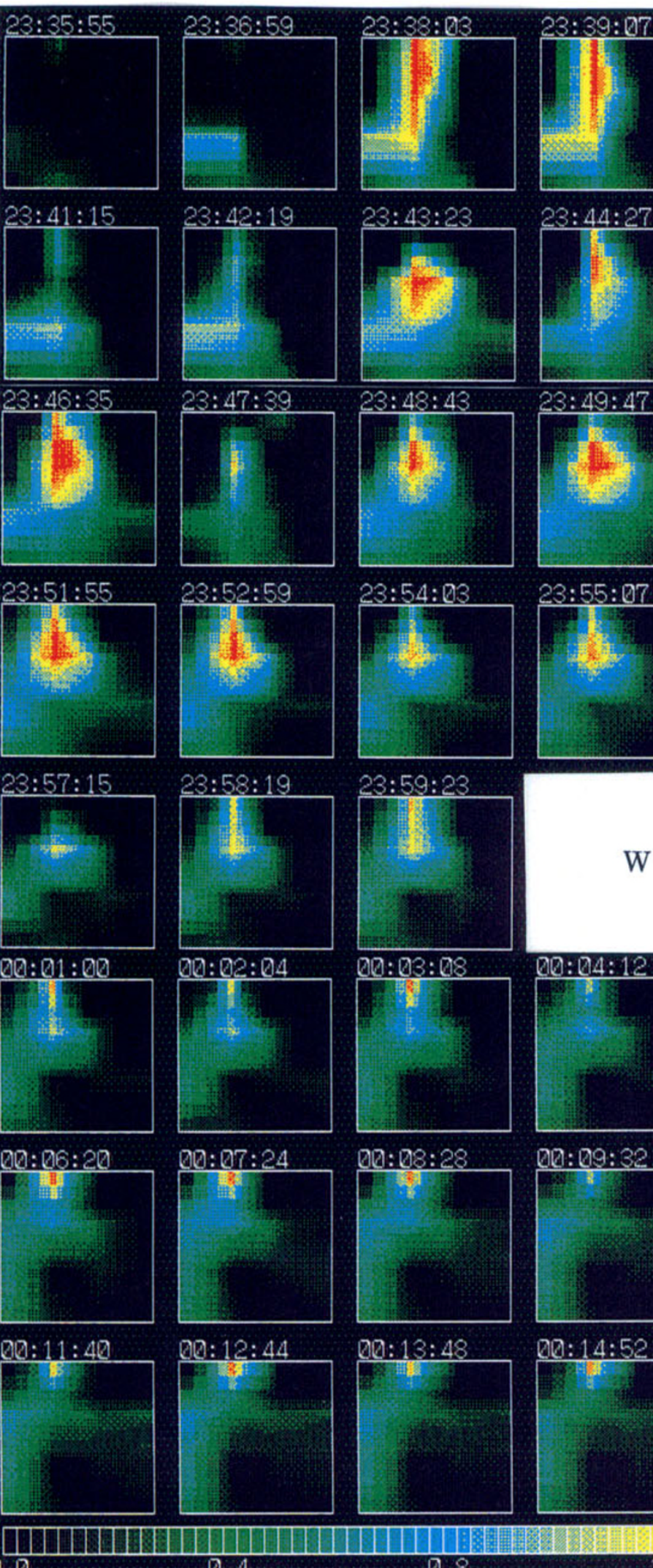

0. 4
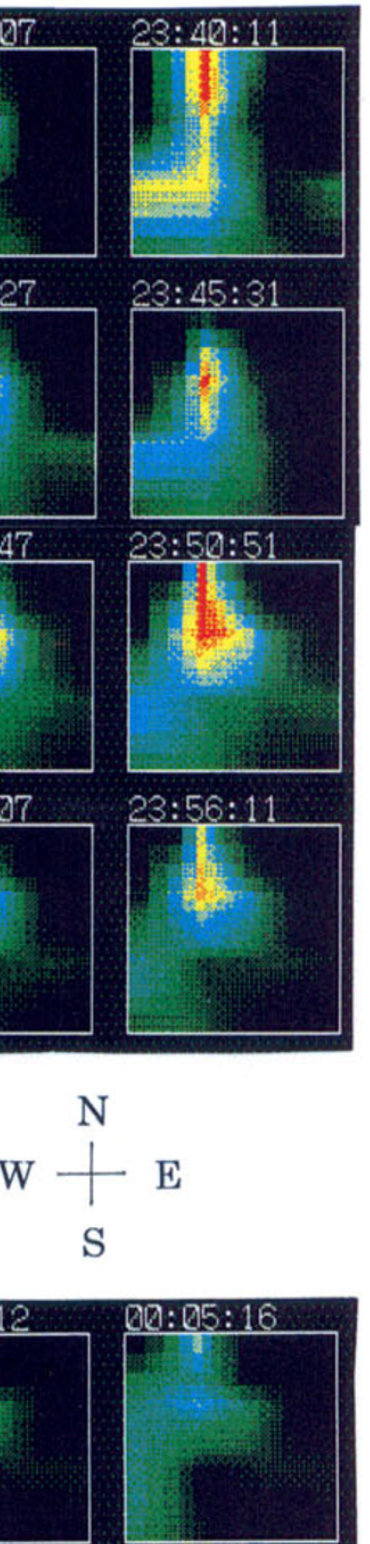

$00: 10: 36$

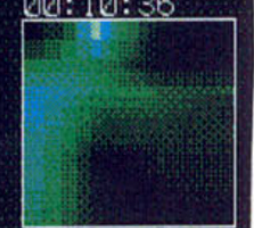

믹: $15: 56$

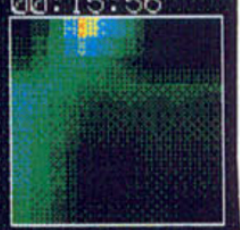

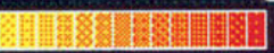

Plate 1. A time series of the absorption images on September 22-23, 1999. Each image is displayed as the average during 64 seconds. Top is north, left is west. Absorption intensity is displayed by color-codes below. 
We summarize characteristics of the present unusual absorption observed during the strong geomagnetic storm on September 22-23, 1999, as follows.

1) The geomagnetic horizontal component showed positive short-period fluctuations and a subsequent sharp decrease with a few positive excursions, and attained to the maximum depression near $21 \mathrm{~h} \mathrm{LT}$. The unusual absorption was observed with short time-duration of 30 45 minutes near the maximum depression and the following positive excursion.

2) The unusual absorption showed two characteristic features: One feature is the sheet structure extended longitudinally at the high-latitude part of the FOV, showing an eastward drift from the western to eastern parts and the subsequent retreat to the western part. Another feature is the meridionally elongated structure with a longitudinal small-scale width $(100 \sim 150 \mathrm{~km})$ from the zenith to the low-latitude part of the FOV and a subsequent localized structure with gradual decay.

First we refer the geomagnetic conditions characterizing precipitation of energetic electrons from the past observations in the SAMA region. Abdu et al. (1973) observed the unique absorption feature near $21 \mathrm{~h}$ LT in Brazil during the geomagnetic disturbance with the sudden commencement followed by the positive short-period fluctuations, the sharp decrease, the maximum depression and the recovery. The unique absorption with time-duration of 30-60 minutes corresponded to the time period of the positive excursions around the maximum depression. This geomagnetic variation is similar to that on the present unusual absorption.

On the other hand, Batista and Abdu (1977) demonstrated significant enhancements on the $E_{S}$-layer parameters in the SAMA region during the time-periods (2-3 hours) after the moderate magnetic storm. Abdu et al. (1981) demonstrated enhancements of the $E_{s}$-layer parameters and lowering of the VLF reflection level in the SAMA region with some delay with respect to the magnetic disturbance onset. They suggested some degree day-to-day variability in the abundance of metallic species and/or in the dynamics of the $E$-region over the SAMA.

Pinto and Gonzaletz (1986) observed an intensification of X-ray fluxes between 30 and $150 \mathrm{keV}$ in association with a strong geomagnetic storm (maximum $\left|D_{s t}\right|=291 \mathrm{nT}$ ) by the balloon-borne experiments in the SAMA. Jayanthi et al. (1997) observed cosmic X-ray fluxes in the energy range between 18.6 to $120 \mathrm{keV}$ by the balloon-borne experiment during a mild storm. They suggested the diffusion of particles from higher $L$ regions into flux tubes connected the SAMA region, due to electric field fluctuations associated with succession of substorms. As described above, the geomagnetic conditions characterizing particle precipitation into the SAMA region are not necessarily definite. Here we investigate substorm occurrences with regards to the present unusual absorption event.

Around 2000 UT on September 22 when was about 3.5 hours prior to the unusual absorption, the $B_{z}$-component of the interplanetary magnetic field (IMF) from the IMP8 satellite suddenly and largely changed to the southward
(-25 nT). Responding to this IMF change, step-wise decreases on the geomagnetic X-components were recorded on the IMAGE Svalbard magnetometer network, and they attained to the maximum depression $(-1000 \mathrm{nT} \sim-1500 \mathrm{nT})$ at about 2145 UT (Lühr et al., 1998), indicating substorm occurrences. Among the IMAGE Scandinavian magnetometer stations (60-72 MLAT), as shown in Fig. 6, the magnetic $\mathrm{X}$-components at the subauroral stations (OUJ, HAN and NUR) attained to the maximum depression at about $2230 \mathrm{UT}$, followed by some positive excursions in substorm recovery phase. Therefore it is concluded that the unusual absorption commenced at $\sim 2330$ UT is associated with the substorms prior to and near the maximum depression during the strong geomagnetic storm.

Next we pay attention to the characteristic feature of the eastward drift of the unusual absorption appeared at the highlatitude part (Fig. 5). Here we estimate electron energies from the eastward drift velocity $(\sim 250 \mathrm{~m} / \mathrm{s}$, assuming an altitude of $100 \mathrm{~km})$ of the sheet absorption.

Abdu et al. (1973) have inferred that the drift motion of the riometer absorption is subjected to an $\mathbf{E} \times \mathbf{B}$ drift in addition to the drift by the magnetic field gradient in the plasmasphere. They gave the following relationship between the observed drift rate of electrons (in degrees per second that the guiding center of the particle makes at the center of the earth) and the drifts due to the magnetic gradient and the $\mathbf{E} \times \mathbf{B}$ force:

$$
\left(58 / R_{0} L\right)(d / d t)=(6 / 44) L e-58\left(\mathbf{E} / B_{e q} R_{0}\right) L^{2} .
$$

$d$ is ionospheric separation between the axes of the two antenna beams, and $d t$ is the time difference, and thus $(d / d t)$ corresponds to the velocity of the absorption drift in the absorption altitude. $L$ is the corresponding magnetic shell parameter, $R_{0}$ is the radius of the earth, $e$ is the electron energy in $\mathrm{MeV}, B_{e q}$ is the surface magnetic field intensity and $\mathbf{E}$ is the electric field, which here is considered positive if directed upward in the equatorial plane and negative if downward. Giving $L=1.2$ and $B_{e q}=0.312$ Gauss, and assuming electric fields, we can estimate electron energy from the above relationship. Here we refer upward plasmaspheric electric fields of $1.8 \mathrm{mV} / \mathrm{m}$ mapped to the equatorial plane near $23 \mathrm{~h}$ MLT at $L \sim 1.6$ which was measured by the S3-3 satellite during strong geomagnetic activity $\left(\left|D_{s t}\right|>100 \mathrm{nT}\right)$ (Gonzalez et al., 1986). Then we obtain electron energies of $16.2 \mathrm{keV}$. If we assume $10 \%$ error for the velocity, electron energy is in the range of $15.1 \mathrm{keV}$ to $17.4 \mathrm{keV}$, which could cause maximum ionization at the lower $E$-region of $\sim 100$ $\mathrm{km}$ altitude (Rees, 1963).

Thus we infer that energetic electrons are injected from the nightside plasma sheet associated with the substorm succession from $20 \mathrm{~h} \mathrm{UT}$, which are represented for the positive short-period geomagnetic fluctuations during the storm initial phase. The energetic electrons should drift eastward encircling the Earth, and thereafter the electrons would precipitate into the SAMA ionosphere associated with the geomagnetic positive excursions near the maximum depression of $0 \mathrm{~h} \mathrm{UT}$. This inference is a little different with the suggestion by Trivedi et al., (1973) that the short-period magnetic fluctuations are directly responsible for higher-energy $(>1$ $\mathrm{MeV}$ ) precipitating flux, which could cause the $D$-region 


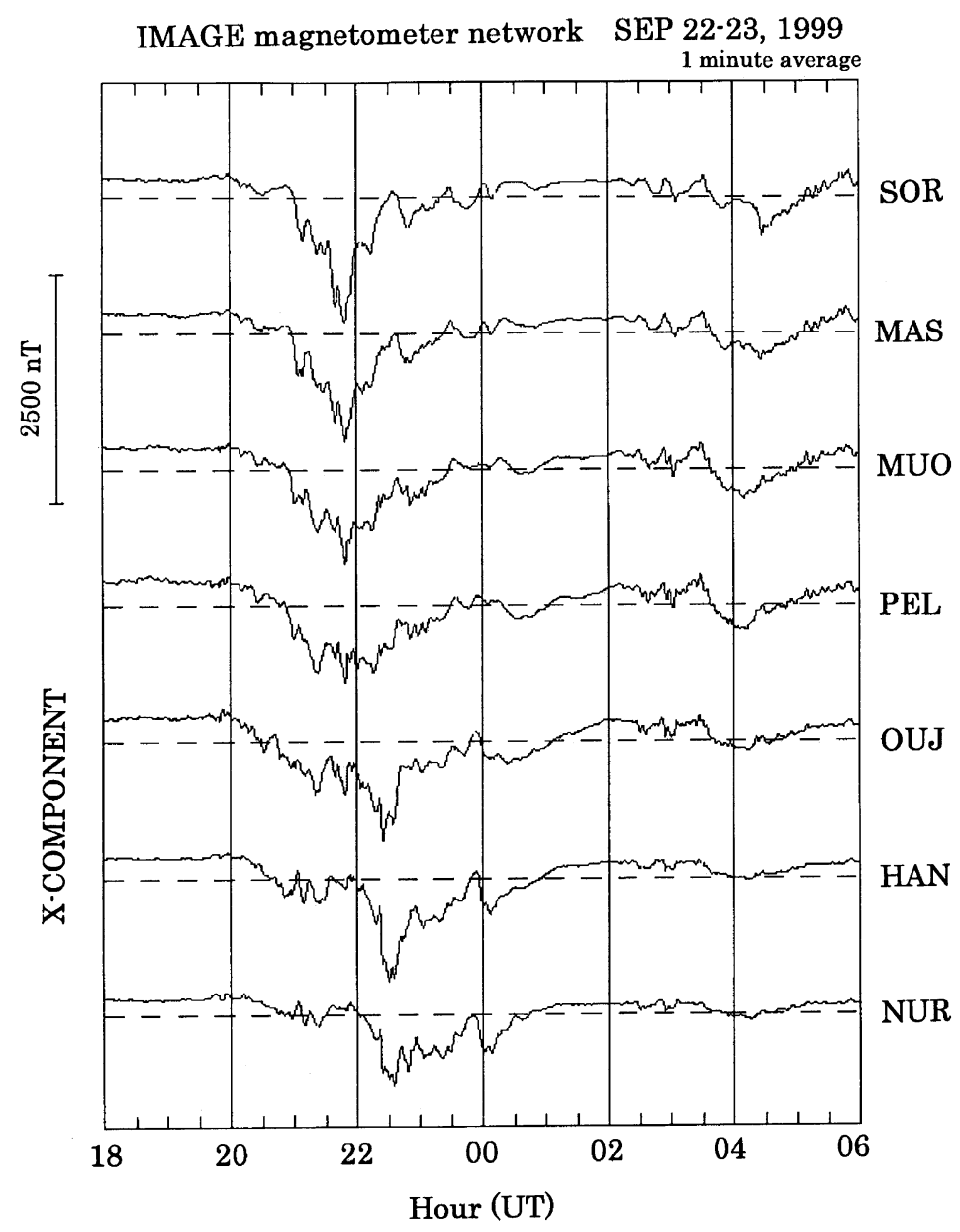

Fig. 6. Geomagnetic X-component variations on September 22-23, 1999 at the Scandinavian stations in the IMAGE magnetometer network. The variations are plotted by 1 min average.

ionization enhancement.

In Plate 1, we notice that the sheet absorption is enhanced simultaneously with the meridionally elongated absorption at 2338:03 UT. The enhancements repeat at 2343:23 UT and 2348:43 UT with the drift motion, and thereafter retreat to the western part in the FOV. This behavior should be compared with the calculation results by Torr et al. (1975): Assuming that the mirror height is $100 \mathrm{~km}$ at $L=1.8$ in the southern hemisphere, they have revealed that precipitated fluxes for $280 \mathrm{keV}$ electrons show a sharp increase (> 35 times greater than the average flux) with very narrow longitudinal width near $30^{\circ} \mathrm{W}$ at $L=1.5$, and show a drastic decrease eastward than $30^{\circ} \mathrm{W}$, implying that stored electrons are drastically precipitated near $30^{\circ} \mathrm{W}$. Although the estimated electron energies $(\sim 20 \mathrm{keV})$ and the concerned $L$-value $(L=1.2)$ for the present unusual absorption are in some degree different with the calculations by Torr et al. (1975), it is qualitatively understood that the present enhancements would be explained as the intensification associated with the sharp increase of the precipitation fluxes, which was induced by the substorm succession during the strong geomagnetic storm.

In the following we discuss the small-scale widths (100$150 \mathrm{~km}$ ) of the meridionally elongated and the localized absorption displayed in Plate 1. Gledhill and Hoffman (1981) demonstrated a sharp peak of downward electron fluxes $(0.2-$
$26.1 \mathrm{keV}$ ) with the ranges of $2-3^{\circ}$ in latitude and $1-2^{\circ}$ in longitude on one orbit over the SAMA region from the AEC satellite observations. Pinto and Gonzalez (1986) detected an intensification of the X-ray fluxes $(30-150 \mathrm{keV})$ in the area covering a longitudinal interval $<4^{\circ}$ at $L=1.13$ from the balloon experiment. Recently Heirtzler and Allen (2002) showed a global distribution of flux of trapped electrons of $>300 \mathrm{keV}$ measured by the NOAA-11 satellite at an altitude of $815 \mathrm{~km}$ during the greatly disturbed period of March 1120,1989 , in which we can find strong fluxes in the area of several hundred kilometers centered near Santa Maria. Actually the strong fluxes may be distributed at the smaller area. Gonzalez et al. (1987) have considered theoretically that the intensification of precipitation could occur in fairly narrow region of the order of a few hundred kilometers at low $L$ values ( $L=1.13$ ), using a numerical simulation of middle atmospheric ionization effect in the atmospheric electric field at stratospheric levels. These observations and the simulation may suggest plausibility of the small-scale enhancements of the present unusual absorption.

Finally, in Fig. 7, we show time variations of the ionospheric parameters $\left(f_{o} F_{2}, h^{\prime} F_{2}\right.$ and $\left.f_{o} E_{s}\right)$ on September 2223, 1999 measured by the ionosonde at Cachoeira Paulista $\left(22.7^{\circ} \mathrm{S}, 45.0^{\circ} \mathrm{W}\right)$ in Brazil, in order to check the ionospheric effect due to electron precipitation. Unfortunately Cachoeira Paulista is separated eastward by about $1000 \mathrm{~km}$ from the 


\section{Ionospheric Parameters}

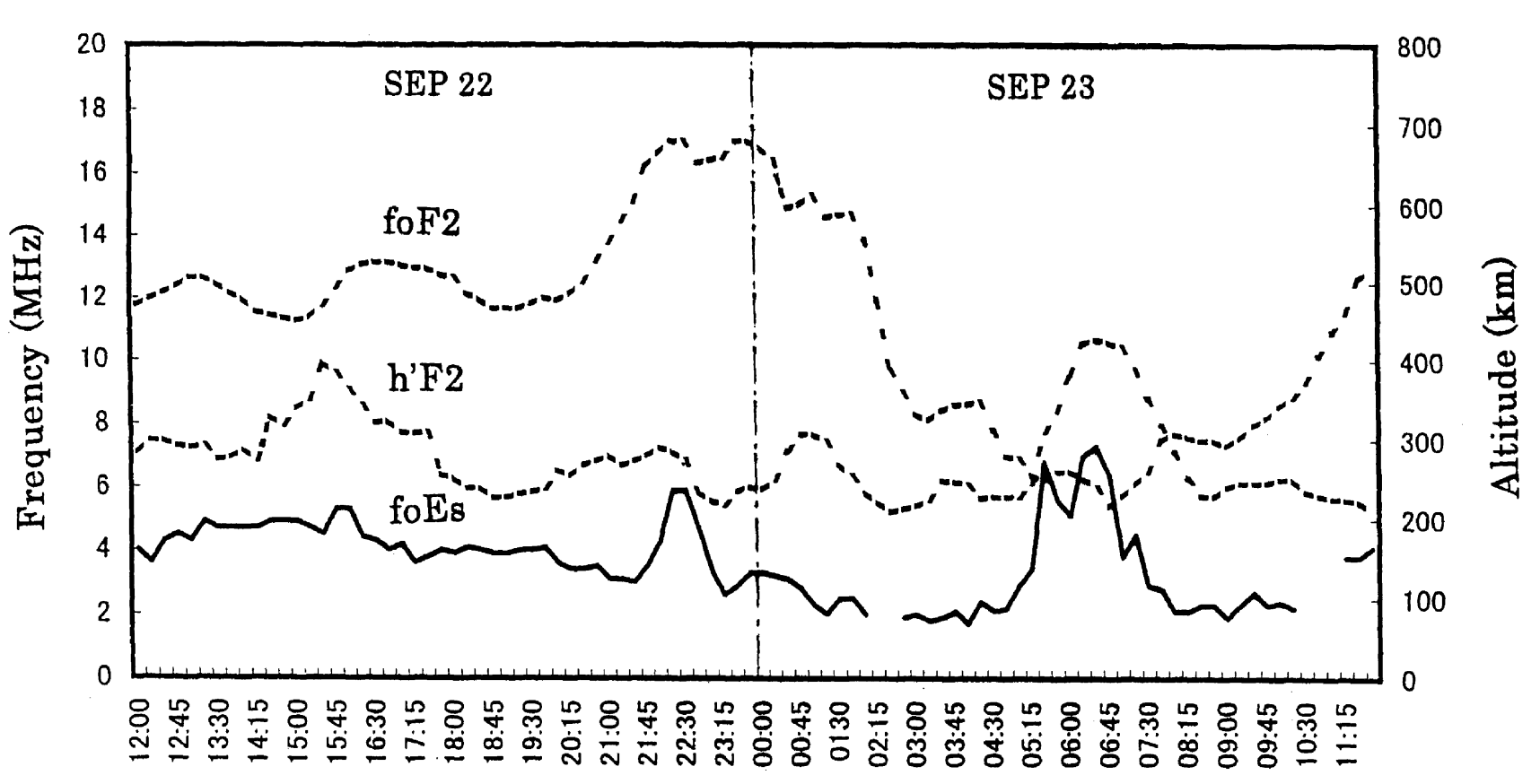

Cachoeira Paulista

UT

Fig. 7. Time variations of ionospheric parameters of $f_{o} E_{s}$ (in frequency), $f_{o} F_{2}$ (in frequency) and $h^{\prime} F_{2}$ (in altitude) on September $22-23,1999$ measured by the ionosonde at Cachoeira Paulista in Brazil. The parameters are measured every 15 min.

IRIS station. In Fig. 7, the $h^{\prime} F_{2}$ shows a step-wise increase at about $14 \mathrm{~h}$ UT, which may correspond to the step-wise absorption increase started at just before $14 \mathrm{~h} \mathrm{UT}$ in Fig. 3. The $f_{o} F_{2}$ increase during $15 \mathrm{~h}-18 \mathrm{~h}$ UT may indicate the usual low-latitude $F$-region absorption from $15 \mathrm{~h} \mathrm{UT}$ in Fig. 3, because the absorption images show expansion in the whole FOV. Thereafter the $f_{o} F_{2}$ shows a large, broad increase attaining to the frequency of $\sim 17 \mathrm{MHz}$ at about $21 \mathrm{~h} \mathrm{UT}$, although the $h^{\prime} F_{2}$ is not so high $(250-300 \mathrm{~km})$. This represents the ionospheric disturbance expanded over the large area in low-latitudes during the main phase to recovery phase. The strong extraneous interference noise extended from the eastern part in the FOV (Fig. 4) must be caused by the ionospheric disturbance.

It should be remarked in Fig. 7 that the $f_{o} E_{S}$ shows an abnormal peak exceeding $6 \mathrm{MHz}$ between $2145 \mathrm{UT}$ and 2315 UT. If the electrons of $\sim 20 \mathrm{keV}$ energies precipitate, the $f_{o} E_{s}$ peak would be appropriate. However, the facts that the $f_{o} E_{s}$ peak is advanced by about $1 \mathrm{~h}$ comparing to the time-period of the unusual absorption and also that the unusual absorption could not drift eastward outside the IRIS FOV (Plate 1) seem to be unreasonable. Consequently the unusual absorption characterizing energetic electron precipitation over the IRIS station was not definitely detected by the measurements of ionospheric parameters at Cachoeira Paulista.

\section{Concluding remarks}

We have presented the unusual absorption event observed at night in the SAMA region. The unusual absorption was observed near the maximum depression and the following positive excursion during the strong geomagnetic storm, which indicates the association with the substorm occurrences. The absorption showed the two characteristic features: One feature is the sheet structure absorption appearing at the high-latitude part with the eastward drift and subsequent retreat. Another feature is the meridionally elongated structure absorption with the longitudinally small-scale, enhanced simultaneously with the sheet absorption. These features reveal that the eastward drifting electrons injected from the nightside plasma sheet would precipitate into the SAMA ionosphere in asymmetric geomagnetic environment between the northern and southern hemispheres. However, it needs more discussions of precipitation processes after further identifications of unusual absorption events during strong geomagnetic storms. Simultaneous satellite particle data will be helpful for discussions of dynamics of energetic electrons in the inner radiation belt.

Acknowledgments. This project is progressed in collaboration with Instituto Nacional de Pesquisas Espacias (INPE) and Federal University of Santa Maria in Brazil. This work is partly supported by Monbu-Kagaku-Syo International Scientific Research Program. One of authors, K. Makita, was supported by Science and Engineering Institute in Takusyoku University. We thank Y. Kato and M. Sato, STE Laboratory, Nagoya University, for the production of the IRIS's antenna and the data procession system. The antenna installation at the INPE-SSO is assisted by students in Laboratorio de Ciencias Espaciais de Santa Maria, to whom we thank very much. The geomagnetic data are provided by WDC-C2 for Geomagnetism, Kyoto University. The IMF data and IMAGE chain magnetic data are provided through the web site, to which we thank very much. 


\section{References}

Abdu, M. A., S. S. Degaonkar, and K. R. Ramanathan, Attenuation of galactic noise at $25 \mathrm{MHz}$ and $21.3 \mathrm{MHz}$ in the ionosphere over Ahmedabad during 1957-1964, J. Geophys. Res., 72, 1547-1554, 1967. Abdu, M. A., S. Ananthakrishman, E. F. Coutinho, B. A. Krishnan, and S. Reis, Azimuthal drift and precipitation of electrons into the South Atlantic geomagnetic anomaly during a SC magnetic storm, J. Geophys. Res., 78, 5830-5836, 1973

Abdu, M. A. and I. S. Batista, Sporadic E-layer phenomena in the Brazilian geomagnetic anomaly; evidence for a regular particle ionization sources, J. Atmos. Terr. Phys., 39, 723-731, 1977.

Abdu, M. A., I. S. Batista, L. R. Piazza, and O. Massambani, Magnetic storm associated enhanced particle precipitation in the South Atlantic anomaly: Evidence from VLF phase measurements, J. Geophys. Res., 86, 7533-7542, 1981.

Abel, B. and R. M. Thorne, Modeling energetic electron prcipitation near the South Atlantic anomaly, J. Geophys. Res., 104, 7037-7044, 1999.

Baker, D. N., J. B. Blake, L. B. Callis, J. R. Cummings, D. Hovestadt, S. Kanekal, B. Klecker, R. A. Mewaldt, and R. D. Zwickl, Relativistic electron acceleration and decay time scales in the inner and outer radiation belts: SAMPEX, Geophys. Res. Lett., 21, 409-412, 1994.

Badhwar, G. D., Drift rate of the South Atlantic Anomaly, J. Geophys. Res. 102, 2343-2349, 1997.

Batista, I. S. and M. A. Abdu, Magnetic storm associated delayed sporadic E enhancements in the Brazilian geomagnetic anomaly, J. Geophys. Res., 82(29), 4777-4783, 1977.

Detrick, D. and T. J. Rosenberg, A phased array radio wave imager for studies of cosmic noise absorption, Radio Sci., 25, 325-338, 1990.

Gledhill, J. A., Aeronomic effects in the South Atlantic anomaly, Rev Geophys. Space Res., 14, 173-187, 1976

Gledhill, J. A. and R. A. Hoffman, Nighttime observation of $0.2-$ to $26 \mathrm{keV}$ electrons in the South Atlantic anomaly made by Atmospheric Explorer C, J. Geophys. Res., 86, 6739-6744, 1981.

Gonzalez, W. D., S. L. G. Dutra, and O. Pinto, Jr, Middle atmospheric electrodynamic modification by particle precipitation at the South Atlantic Magnetic Anomaly, J. Atmos. Terr. Phys., 49, 377-383, 1987.

Gonzalez, W. D., O. Pinto, Jr., and O. Mendes, Jr., Large plasmaspheric electric fields at $L \sim 2$ measured by the S3-3 satellite during strong geomagnetic activity, Geophys. Res. Lett., 13, 363-365, 1986.

Heirtzler, J. R. and J. H. Allen, Ever-present South Atlantic anomaly damages spacecraft, EOS Trans. AGU, 83(15), 165/169, 2002.

Jayanthi, U. B., M. G. Pereira, I. M. Martin, Y. Stozkov, F. D’Amico, and T. Villela, Electron precipitation associated with geomagnetic activity: Balloon observation of X ray flux in South Atlantic anomaly, J. Geophys Res., 102, 24069-24073, 1997.

Kikuchi, T. and D. S. Evans, Energetic electrons observed by NOAA-6 over Japan $(L=1.3)$ at the time of geomagnetic storm on February $8-9,1986$,
Proc. Res. Inst. Atmos., Nagoya Univ., 36, 137-149, 1989

Kohno, T., K. Munakata, K. Nagata, H. Murakami, A. Nakamoto, N. Hasebe, J. Kikuchi, and J. Doke, Intensity maps of MeV electrons and protons below the radiation belt, Planet. Space Sci., 38, 483-490, 1990.

Lühr, H., A. Aylward, S. C. Bucher, K. Pajunpaa, T. Holmboe, and S. M. Zalewski, Westward moving substorm features observed with the IMAGE magnetometer network and the ground-based instruments, Ann. Geophys., 16, 425-440, 1998.

Nishino, M., Y. Tanaka, T. Oguti, H. Yamagishi, and J. A. Holtet, Initial observation results with imaging riometer at Ny Ålesund $(L=16)$, Proc. NIPR Symp. Upper Atmos. Phys., 6, 47-61, 1993.

Obara, T., M. Den, Y. Miyoshi, and A. Morioka, Energetic electron variation in the outer radiation zone during early May 1998 magnetic storm, $J$. Atmos. Solar-Terr. Phys., 62, 1405-1412, 2000.

Paulikas, G. A., Precipitation of particles at low and middle latitudes, Rev. Geophysics and Space Physics, 13, 709-734, 1975.

Pinto, Jr., O. and W. D. Gonzalez, X ray measurements at the South Atlantic magnetic anomaly, J. Geophys. Res., 91, 7072-7078, 1986.

Pinto, Jr., O. and W. D. Gonzalez, Energetic electron precipitation at the South Atlantic magnetic anomaly: a review, J. Atmos. Terr. Phys., 51(5), 351-365, 1989.

Pinto, Jr., O., W. D. Gonzalez, and N. M. Paes Leme, VLF disturbances at the South Atlantic Magnetic Anomaly following magnetic storms, Planet. Space Sci., 38, 633-636, 1990.

Rees, M. H., Auroral ionization and excitation by incident energetic electrons, Planet. Space Sci., 11, 1209, 1963.

Sato, M., H. Yamagishi, Y. Kato, and M. Nishino, Quick-look system of auroral absorption images by imaging riometer, Antarctic Rec., 36, 251267, 1992 (in Japanese with English abstract).

Stauning, P., S. Henriksen, and H. Yamagishi, Imaging riometer installation in Danmarkshavn, Greenland, Danish Meteorological Institute, Technical Rep, 92-4, 1-25, 1992.

Takeda, M., T. Iyemori, and T. Kamei, World Data Center for Geomagnetism, Data Catalogue, 25, 133, 1999.

Torr, D. G., M. R. Torr, and J. C. G. Walker, Particle precipitation in the South Atlantic geomagnetic anomaly, Planet. Space Sci., 23, 15-26, 1975.

Trivedi, N. B., D. B. Rai, I. M. Martin, and J. M. Da Costa, Particle precipitation in Brazilian geomagnetic anomaly during magnetic storms, Planet. Space. Sci., 21, 1699-1704, 1973

Vampola, A. L. and D. J. Gorney, Electron energy deposition in the middle atmosphere, J. Geophys. Res., 88, 6267-6274, 1983.

M. Nishino (e-mail: nishino@stelab.nagoya-u.ac.jp), K. Makita, K. Yumoto, F. S. Rodrigues, N. J. Schuch, and M. A. Abdu 